\title{
Loxosceles gaucho spider venom and its sphingomyelinase fraction trigger the main functions of human and rabbit platelets
}

Human and Experimental Toxicology 30 (10) 1567-1574 (C) The Author(s) 2011 Reprints and permission: sagepub.co.uk/journalsPermissions.nav DOI: $10.1177 / 096032711039376$ het.sagepub.com @SAGE

\author{
Flávio L Tavares', María E Peichoto², \\ Danieli de Morais Rangel ${ }^{3}$, Kátia C Barbaro ${ }^{3}$, \\ Maria Cristina Cirillo', Marcelo L Santoro' and \\ Ida S Sano-Martins'
}

\begin{abstract}
Loxosceles venoms can promote severe local and systemic damages. We have previously reported that Loxosceles gaucho spider venom causes a severe early thrombocytopenia in rabbits. Herein, we investigated the in vitro effects of this venom and its sphingomyelinase fraction on the main functions of platelets. Whole venom and its fraction induced aggregation of both human and rabbit platelets. Aggregation was dependent of plasma component(s) but independent of venom-induced lysophosphatidic acid generation. There was no increase in the levels of lactate dehydrogenase during platelet aggregation, ruling out the possibility of platelet lysis. The increased expression of ligand-induced binding site I (LIBSI) induced by $L$. gaucho venom and its sphingomyelinase fraction, as well as of P-selectin by the whole venom, evidenced the activation state of both human and rabbit platelets. Adhesion assays showed an irregular response when platelets were exposed to the whole venom, whereas the sphingomyelinase fraction induced a dose-dependent increase in the platelet adhesion to collagen. These findings evidence that $L$. gaucho venom and its sphingomyelinase fraction trigger adhesion, activation, and aggregation of both human and rabbit platelets. Thus, this work justifies the use of rabbits to investigate Loxosceles venom-induced platelet disturbances, and it also supports research on the role of platelets in the pathogenesis of loxoscelism.
\end{abstract}

\section{Keywords}

Loxosceles gaucho, venom, sphingomyelinase, platelet activation, platelet adhesion, platelet aggregation

\section{Introduction}

Spiders belonging to the genus Loxosceles, popularly known as brown spiders, are widespread from equatorial to subtemperate regions of the world. ${ }^{1}$ Envenomation by Loxosceles sp may result in a necrotizing-hemolytic syndrome, loxoscelism, which is considered the most important form of araneism in South America, where the main species of medical importance are L. laeta, L. intermedia and L. gaucho. ${ }^{2}$

The hallmark of the loxoscelism is the development of a dermonecrotic wound at the bite site, which is histologically characterized by edema, extensive intradermal and subcutaneous hemorrhage, polymorphonuclear infiltration, thrombus and extravascular fibrin deposition that progress to an ulterior aspect of fibrinoid necrosis. ${ }^{1,2,3}$ Although less frequent, human accidents may evoke severe systemic disturbances, such as intravascular hemolysis and disseminated intravascular coagulation, which may result in

\footnotetext{
' Laboratório de Fisiopatologia, Instituto Butantan, São Paulo-SP, Brazil

2 Facultad de Ciencias Veterinarias, Universidad Nacional del Nordeste, Corrientes, Argentina

${ }^{3}$ Laboratório de Imunopatologia, Instituto Butantan, São Paulo-SP, Brazil
}

Corresponding author:

Flávio L Tavares, Instituto Butantan, Laboratório de Fisiopatologia, Av. Vital Brazil, I500, 05503-900, São Paulo-SP, Brazil

Email: flutavares@gmail.com 
renal failure and death. ${ }^{4,5}$ We have previously verified that rabbits injected intradermally with L. gaucho whole venom develop severe early thrombocytopenia, but this phenomenon is not related to systemic loxoscelism since intravascular hemolysis and disseminated intravascular coagulation could not be verified in this experimental model. ${ }^{6}$

The sphingomyelinase activity of $30-35 \mathrm{kDa}$ proteins from Loxosceles sp venom has been described as the main mechanism in the induction of dermonecrosis, and the mediation of complex and multifactorial processes, such as complement activation and interactions between venom components and the cell membrane and/or extracellular matrix. ${ }^{7-10}$ Among other effects, Loxosceles venoms and their toxins exhibiting sphingomyelinase activity induce platelet aggregation in vitro. ${ }^{11-14}$ However, it is unknown whether it could be the result of either agglutination or platelet lysis. In addition, the effects of Loxosceles venoms on other platelet functions, such as adhesion and activation, have not been studied yet.

Thus, in the present study, we investigated the in vitro actions of $L$. gaucho whole venom and its sphingomyelinase fraction on the main functions of platelets: activation, adhesion and aggregation. Moreover, in order to extrapolate experimental studies in animals to the human envenomation, and taking into account that rabbit is the most used experimental animal model to investigate loxoscelism, we also compared the effects of $L$. gaucho venom and its sphingomyelinase fraction on both human and rabbit platelets.

\section{Material and methods}

\section{Loxosceles gaucho venom and its sphingomyelinase $35-k D a$ fraction}

Specimens of L. gaucho were collected in São Paulo State, Brazil. After electrostimulation of the cephalotorax region, spider venom extraction was performed by micropipette aspiration. The venom extracted of hundred of spiders was pooled and frozen until the moment of use, as previously described. ${ }^{15}$

The protein content was determined by the bicinchoninic acid assay, ${ }^{16}$ using bovine serum albumin (BSA) (Sigma-Aldrich, USA) as standard. The studied fraction from $L$. gaucho venom was purified using a Mono-S column, as reported by Cunha et al. ${ }^{17}$ This fraction showed a single band of $35 \mathrm{kDa}$ by SDS-PAGE, and it was able to induce dermonecrosis in rabbits and exhibited sphingomyelinase activity assayed as described previously. $^{7}$

\section{Platelet aggregation assay}

Human blood was withdrawn from the brachial vein of healthy volunteers and then mixed with $3.8 \%$ trisodium citrate $(9: 1, v / v)$. Only donors declaring that they had not used any drugs known to interfere with platelet function for at least 14 days earlier were included in this study. Rabbit blood was withdrawn from the auricular central artery through a butterfly scalp needle $(21 \mathrm{~g})$ and then added to $3.8 \%$ trisodium citrate $(9: 1, v / v)$. For each experiment using human or rabbit blood, a new collection of blood was carried out. The procedures involving animals were performed in accordance with the Guide for the Care and Use of Laboratory Animals (1996; http://www.nap.edu/ readingroom/books/labrats/) and they were approved by the Ethical Committee for the Use of Animals at Butantan Institute (process number 129/2003).

Platelet-rich plasma (PRP) or washed platelets were obtained from fresh blood samples of both species as described previously. ${ }^{18}$ Briefly, PRP was obtained after blood centrifugation $(190 \mathrm{~g}$ ) for $20 \mathrm{~min}$ at room temperature. Washed platelets were obtained from PRP through sequential washings in Tyrode's solution containing prostaglandin $\mathrm{PGE}_{1}$ (SigmaAldrich, USA) and subsequent centrifugations (1900 $\mathrm{g} / 15 \mathrm{~min}$ ) at room temperature. Final platelet count in PRP or washed platelets was adjusted to $300 \times$ $10^{9} / \mathrm{L}$. Platelet aggregation was performed in a chrono-log lumiaggregometer (model 560VS) by the method of Born ${ }^{19}$ and results were expressed in percentage of change in light transmittance.

Whole venom or fraction was diluted in saline solution, and then $10 \mu \mathrm{L}$ of whole venom (20 or $40 \mu \mathrm{g} / \mathrm{mL}$ for human or rabbit platelets, respectively, final concentration) or sphingomyelinase fraction ( 2 or $4 \mu \mathrm{g} / \mathrm{mL}$ for human or rabbit platelets, respectively, final concentration) were added to $400 \mu \mathrm{L}$ of PRP. The intensity of platelet aggregation was measured for $10 \mathrm{~min}$. The positive control consisted of human or rabbit PRP incubated with collagen (Chrono-log, USA) in a final concentration of 2 or $4 \mu \mathrm{g} / \mathrm{mL}$, respectively.

As it is possible that venom sphingomyelinases act on lysophasphatidylcholines (LPC) to generate lysophosphatidic acid (LPA), which is known to mediate platelet activation through the stimulation of the $\mathrm{LPA}_{1}$ and $\mathrm{LPA}_{3}$ receptors, ${ }^{20}$ the participation of the LPA pathway in the platelet aggregation induced by L. gaucho venom was investigated. Human and rabbit PRP were incubated with both venom (in the same concentrations described above) and dioctanoylglycerol 
pyrophosphate (DGPP 8:0; Avanti Polar Lipids, USA), a selective antagonist of the $\mathrm{LPA}_{1}$ and $\mathrm{LPA}_{3}$ receptors, ${ }^{20}$ in the concentrations of 20 to $40 \mathrm{mM}$; 1 acyl(20:4) glycerophosphate (LPA 20:4; Avanti Polar Lipids, USA) was used as a positive control (concentrations of 20 to $40 \mathrm{mM}$ ) to induce platelet aggregation.

\section{Lactate dehydrogenase leakage}

In order to verify platelet lysis induced by the venom, PRP was incubated with $L$. gaucho whole venom as described above. After aggregation, it was centrifuged at $1900 \mathrm{~g}$ for $15 \mathrm{~min}$. The supernatant was used to determine the leakage of lactate dehydrogenase (LDH) from platelets, according to a modification of the method described by Burtis and Ashwood. $^{21}$

\section{Flow cytometry of platelets}

In order to determine the expression of activation markers on platelet membrane, human or rabbit PRP incubated with venom or its fraction was used for flow cytometry studies. Briefly, 1 volume of $2 \%$ paraformaldehyde in phosphate buffered saline (PBS, $\mathrm{pH}$ 7.4) was added to 1 volume of PRP and then incubated with antibody-saturated solution. The labeling intensity of fluorescein isothiocyanate-conjugated (FITC-conjugated) or phycoerythrin-conjugated (PE-conjugated) antibodies was evaluated in PRP exposed to L. gaucho venom or its fraction and compared with quiescent or collagen-activated platelets. The following monoclonal antibodies were employed: FITC-conjugated anti-rabbit GPIIb-IIIa IgY, which reacts with both rabbit and human platelets ${ }^{22}$; anti-ligand-induced binding site (anti-LIBS1; kind donation of Dr Mark H Ginsberg, Scripps Research Institute, La Jolla, USA), an antibody that recognizes the ligand-induced binding site 1 (LIBS1) of human GPIIIa following occupation of GPIIb-IIIa by either fibrinogen or peptides that contain the sequence RGD or HHLGGAKQAGDV, ${ }^{23}$ and that also cross reacts with rabbit GPIIIa ${ }^{22}$; $12 \mathrm{~A} 7$ (kind donation of Dr Guy Reed, Harvard School of Public Health, Boston, USA), an antibody that specifically reacts with rabbit platelet P-selectin ${ }^{24}$; PE-conjugated anti-human CD62P (Pharmingen, USA), that reacts specifically with human P-selectin.

Platelets were exposed, under the aggregation conditions described previously, to venom, its fraction or collagen (positive control) for $10 \mathrm{~min}$. Quiescent platelets (negative control) remained under agitation for the same time at $37^{\circ} \mathrm{C}$. Thereafter, each sample was fixed with an equal volume of $2 \%$ paraformaldehyde in PBS. Aliquots of fixed platelet suspension $(25 \mu \mathrm{L})$ were incubated at room temperature in the dark with: (1) anti-LIBS1 $(25 \mu \mathrm{L}, 40 \mu \mathrm{g} / \mathrm{mL})$ or (2) $12 \mathrm{~A} 7(25 \mu \mathrm{L}, 20$ $\mu \mathrm{g} / \mathrm{mL}$ ) for 1 hour, and then $2 \mu \mathrm{L}$ of PE-conjugated goat anti-mouse IgG (Sigma-Aldrich, USA) was added and incubated for 1 hour; (3) PE-conjugated anti-human CD62P (2 $\mu \mathrm{L}, 100 \mu \mathrm{g} / \mathrm{mL})$ for 1 hour; (4) FITCconjugated anti-rabbit GPIIb-IIIa IgY $(2 \mu \mathrm{L}, 500 \mu \mathrm{g} /$ $\mathrm{mL}$ ) for 2 hours. Samples were analyzed on a FACSCalibur flow cytometer (Becton Dickinson, USA). Light scatter and fluorescence data from 10000 events were collected with all detectors in logarithmic mode. Data were saved in flow cytometry list mode files for subsequent analysis in WinMDI software, version 2.8 .

\section{Platelet adhesion assay}

Platelet adhesion to collagen was performed in microplates using a modification of a previously described method. ${ }^{25}$ Microplates were coated with $50 \mu \mathrm{L} /$ well of $40 \mu \mathrm{g} / \mathrm{mL}$ equine collagen Type I (Chrono-log, USA), diluted in $5 \mathrm{mM}$ acetic acid for 2 hours at $37^{\circ} \mathrm{C}$. Microplates were then washed two times by plate inversion with PBS containing $2 \mathrm{mM}$ $\mathrm{MgCl}_{2}$ (modified PBS). Blocking was carried out with $2 \mathrm{mg} / \mathrm{mL}$ BSA for 1 hour at $37^{\circ} \mathrm{C}$. After washing with modified PBS, $40 \mu \mathrm{L} /$ well of PRP (adjusted to $75 \times 10^{9} / \mathrm{L}$ and $150 \times 10^{9} / \mathrm{L}$ platelets for human and rabbit PRP, respectively) were added to prewarmed microplates at $37^{\circ} \mathrm{C}$, and afterwards $10 \mu \mathrm{L}$ of two-fold serial dilutions of venom or its fraction were added. Plates were incubated for 1 hour under static conditions in a humidified thermostat at $37^{\circ} \mathrm{C}$. At the end of the incubation, plates were washed with PBS and wells were rapidly supplemented with $150 \mu \mathrm{L}$ of $0.1 \mathrm{M}$ citrate buffer, $\mathrm{pH} 5.4$, containing $0.1 \%$ Triton $\mathrm{X}-100$ in order to cause instantaneous lysis of platelets, and $5 \mathrm{mM} p$-nitrophenyl phosphate (Sigma-Aldrich, USA) as substrate for platelet phosphatases. After incubation at $37^{\circ} \mathrm{C}$ for 1 hour, the reaction was stopped and the color was developed by the addition of $100 \mu \mathrm{L}$ of $2 \mathrm{M}$ $\mathrm{NaOH}$. The $p$-nitrophenol produced by the reaction was measured with a microplate reader at $405 \mathrm{~nm}$ against a blank, a platelet-poor plasma (PPP). The percentage of adherent cells was calculated on the basis of a standard curve obtained with known platelet counts in PRP preparations. 


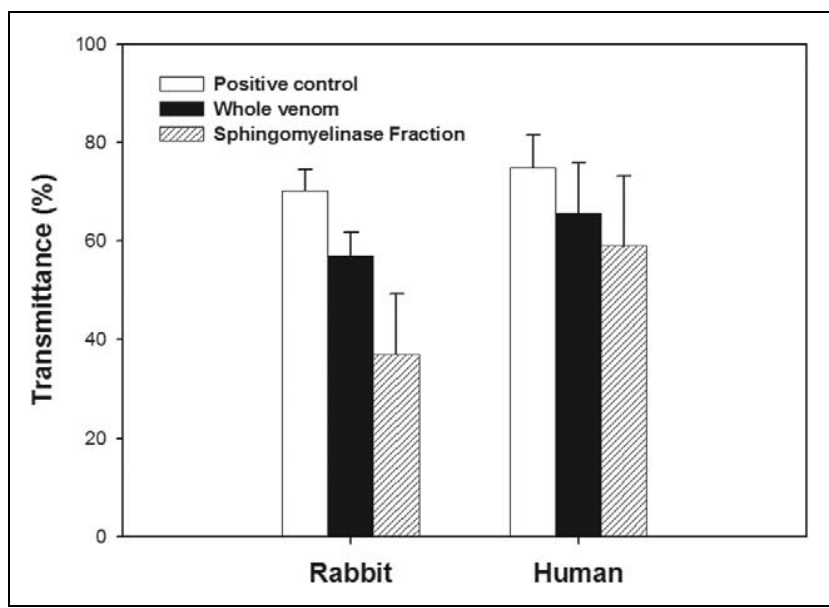

Figure I. Platelet aggregation induced by $L$ gaucho venom and sphingomyelinase fraction in rabbit and human plateletrich plasma (PRP). Human PRP was incubated with $2 \mu \mathrm{g} / \mathrm{mL}$ of collagen (positive control), $20 \mu \mathrm{g} / \mathrm{mL}$ of whole venom or $2 \mu \mathrm{g} / \mathrm{mL}$ of sphingomyelinase fraction. Rabbit PRP was incubated with $4 \mu \mathrm{g} / \mathrm{mL}$ of collagen (positive control), $40 \mu \mathrm{g}$ / $\mathrm{mL}$ of whole venom or $4 \mu \mathrm{g} / \mathrm{mL}$ of sphingomyelinase fraction. Data are expressed as mean $\pm \operatorname{SEM}(n=5)$.

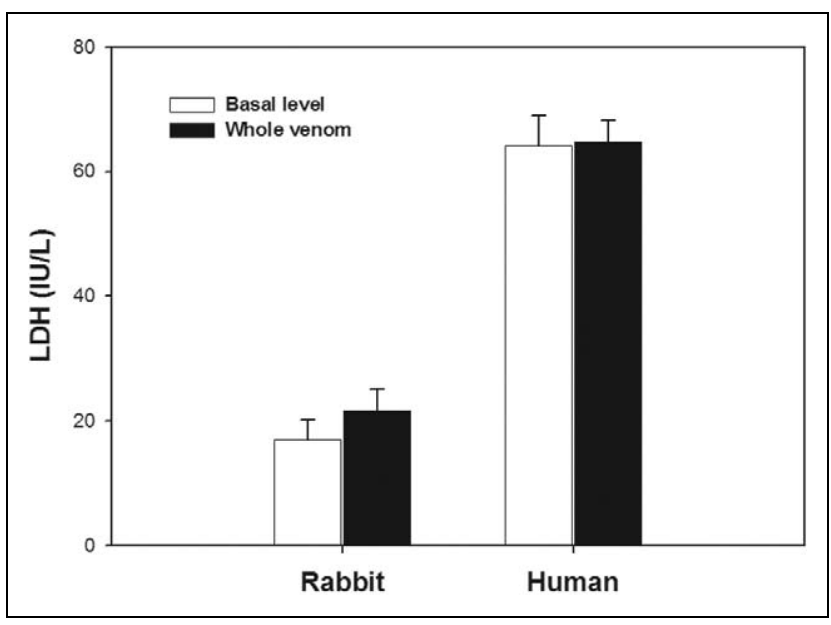

Figure 2. Effect of the incubation of rabbit and human platelet-rich plasma (PRP) with $20 \mu \mathrm{g} / \mathrm{mL}$ and $40 \mu \mathrm{g} / \mathrm{mL}$ $L$. gaucho whole venom, respectively, on lactate dehydrogenase $(\mathrm{LDH})$ leakage. Basal levels were assayed in platelet-poor plasma (PPP) of both species. Data are expressed as mean \pm SEM $(n=5)$.

\section{Statistical analysis}

Two-way ANOVA and Tukey test were used to analyze data and compare the results among the different groups. Statistical analyses were carried out on STATA $^{\text {TM }}$ software version 5.0 and SigmaStat software version 2.03 (SSPS, USA). Differences with $p<0.05$ were considered statistically significant.

\section{Results}

The whole venom of $L$. gaucho spider and its sphingomyelinase fraction were able to induce platelet aggregation when they were exposed to either human or rabbit PRP (Figure 1). The intensity of this response was more evident when human PRP was used, since rabbit platelets required a two-fold higher concentration of venom to reach a similar extent of aggregation. When using washed platelets of both species (without the presence of plasma components), aggregation was not observed in the presence of either whole venom or sphingomyelinase fraction.

Dioctanoylglycerol pyrophosphate was able to inhibit aggregation induced by LPA 20:4, but not that induced by $L$. gaucho whole venom (data not shown). Increase in the levels of LDH during platelet aggregation of either rabbit or human PRP induced by the whole venom under conditions of controlled stirring and temperature was not observed (Figure 2). Since there was no response to the whole venom, the sphingomyelinase fraction was not tested in LPA and LDH experiments.

The study of platelet membrane activation markers by flow cytometry (Figure 3) showed a significant increase $(p<0.05)$ in LIBS1 expression in both human and rabbit platelets exposed to the whole venom and its sphingomyelinase fraction. On the other hand, $\mathrm{P}$-selectin expression was increased in human and rabbit platelets by exposition to the whole venom, but not to the sphingomyelinase fraction. Finally, GPIIb-IIIa expression in platelets of both species was not modified by either the whole venom or its fraction.

Both human and rabbit platelets adhered with high affinity to microplates coated with collagen in a platelet count-dependent manner. Platelet counts of $150 \times 10^{9} / \mathrm{L}$ and $75 \times 10^{9} / \mathrm{L}$ for rabbit and human PRP, respectively, corresponded to the optimum count to be tested for platelet adhesion in the presence of $L$. gaucho whole venom or its fraction. The choice of these platelet counts let us obtain more homogeneous results for concentration-response curves. In the presence of the sphingomyelinase fraction, but not L. gaucho whole venom, platelet adhesion from both rabbit and human PRP responded in a concentrationdependent manner (Figure 4); the percentage increase in platelet adhesion as a function of the sphingomyelinase concentration was more intense in rabbit PRP than in human PRP. In spite of an irregular response caused by the whole venom, platelet adhesion was more intense when using human PRP than rabbit PRP (Figure 4). 


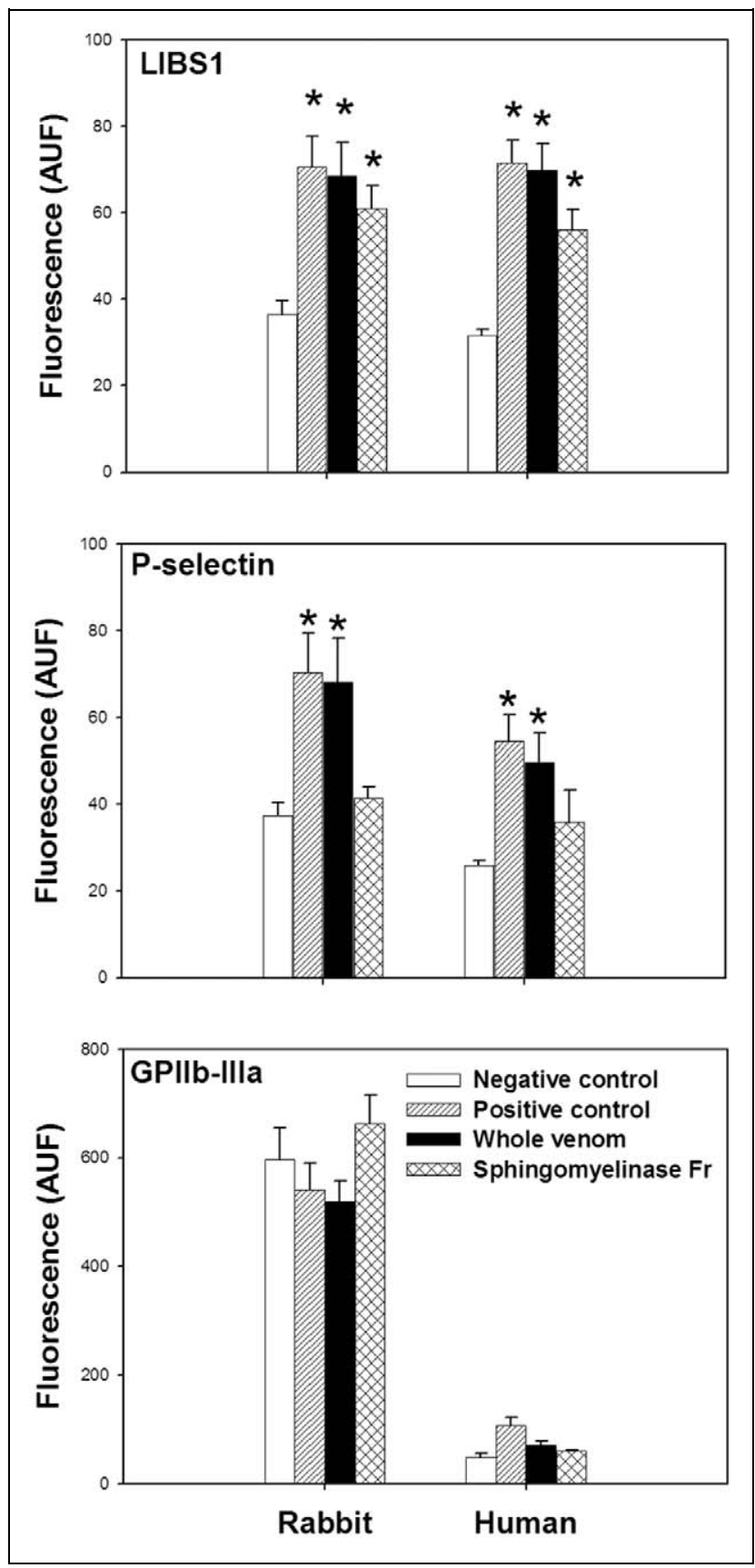

Figure 3. Expression of platelet membrane activation markers: ligand-induced binding site (LIBSI); P-selectin; GPIlb-IIla. They were analyzed by flow cytometry and expressed in arbitrary units of fluorescence (AUF), on rabbit and human platelets incubated with $L$ gaucho whole venom and sphingomyelinase fraction. Human platelet-rich plasma (PRP) was incubated with $2 \mu \mathrm{g} / \mathrm{mL}$ of collagen (positive control), $20 \mu \mathrm{g} / \mathrm{mL}$ of whole venom or $2 \mu \mathrm{g} / \mathrm{mL}$ of sphingomyelinase fraction. Rabbit PRP was incubated with $4 \mu \mathrm{g} / \mathrm{mL}$ of collagen (positive control), $40 \mu \mathrm{g} / \mathrm{mL}$ of whole venom or $4 \mu \mathrm{g} / \mathrm{mL}$ of its fraction. Quiescent platelets were used as negative control for both species. Data are expressed as geometric mean \pm SEM $(n=5) . *_{p}<0.05$ vs negative control.

\section{Discussion}

Loxoscelism is a necrotizing pathological process, which may cause systemic hemolytic and coagulation disorders. Loxosceles venoms and their toxins affect a wide spectrum of substrates as well as disturb diverse types of cells, such as keratinocytes, endothelial cells, leukocytes, red cells and platelets. ${ }^{5,26,27}$ Importantly, we show herein that $L$. gaucho venom and its sphingomyelinase fraction promote activation, adhesion and aggregation of both rabbit and human platelets even in the absence of other cells.

Although the intensity of the aggregation was more evident in human PRP exposed to the whole venom or its fraction, since rabbit platelets required a two-fold higher concentration of venom to reach a similar extent of aggregation, both human and rabbit platelets were susceptible to venom- and sphingomyelinase fraction-induced aggregation. Moreover, LDH levels in the milieu of platelets exposed to the venom were not different from basal levels, ruling out the possibility that the increase in transmittance observed during aggregation assay of human and rabbit PRP was caused by platelet lysis. Furthermore, we confirmed that $L$. gaucho venom-induced platelet aggregation, in PRP of both species, only occurs in the presence of plasma components, such as observed elsewhere for L. reclusa venom in human PRP. ${ }^{14}$

The mechanism of platelet aggregation induced by Loxosceles venoms has been poorly investigated. In the last decade, it was reported that sphingomyelinases cloned from $L$. intermedia and $L$. reclusa venoms promote LPC hydrolysis to generate LPA, ${ }^{28,29}$ which can activate endothelial cells and leukocytes in inflammatory events. ${ }^{30}$ This phospholipid can also induce platelet activation and aggregation. ${ }^{31}$ Our results suggest that L. gaucho venominduced platelet aggregation is not dependent on the LPA pathway, which depends on the activation of $\mathrm{LPA}_{1}$ and $\mathrm{LPA}_{3}$ receptors on platelet surface. ${ }^{20}$ However, a potential participation of the LPA pathway in Loxosceles venom-induced inflammation remains unknown and requires investigation.

In quiescent human platelets, about $20 \%$ of GPIIb-IIIa complexes are on membranes of the $\alpha$-granules and open canalicular system, but depending on activation intensity, they can be exposed on the surface membrane. ${ }^{32}$ Although our results indicate that there were no differences in GPIIb-IIIa expression under any treatment, L. gaucho venom and its fraction induced significant increases in the expression of an important 


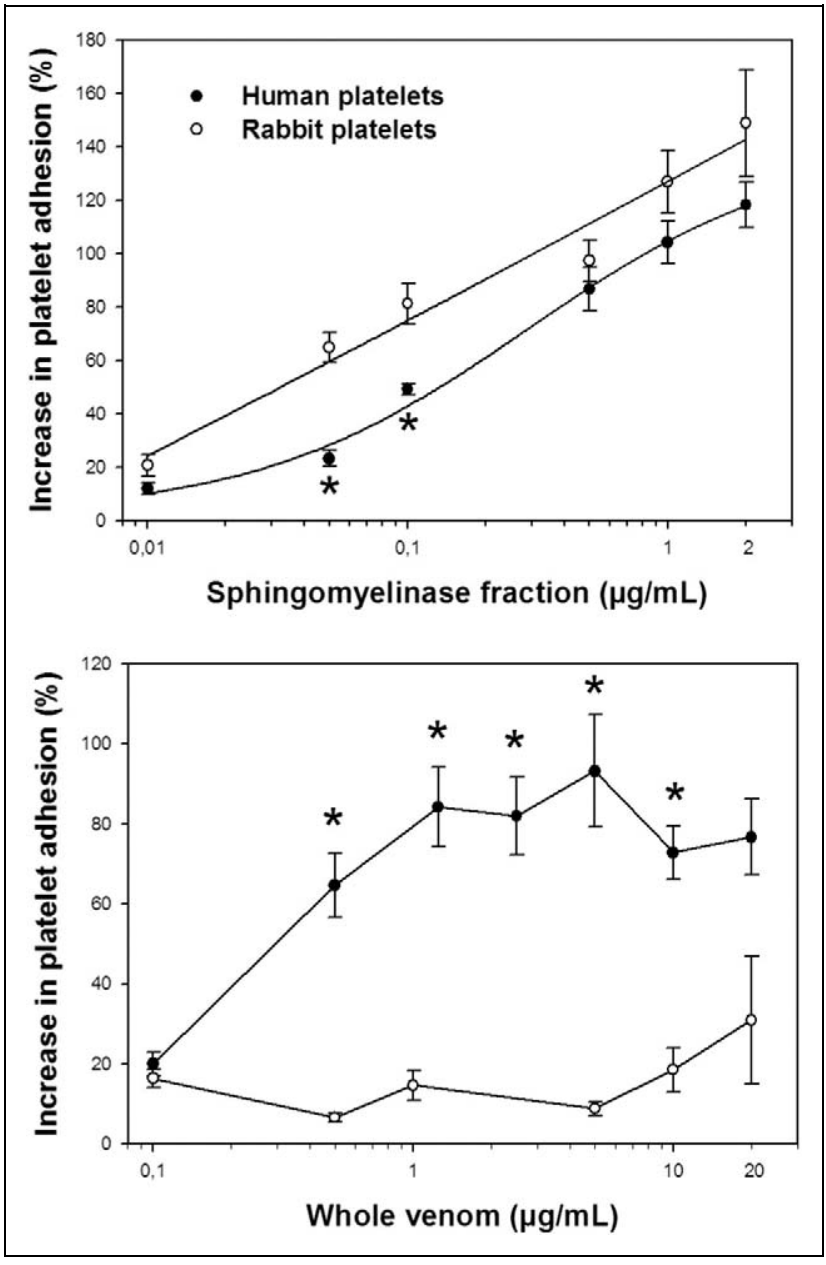

Figure 4. Platelet adhesion of rabbit and human plateletrich plasma (PRP) exposed to: L. gaucho whole venom; sphingomyelinase fraction. Concentration-response curves were analyzed using a fixed platelets count (rabbit: $150 \times$ $10^{9} / \mathrm{L}$; human: $75 \times 10^{9} / \mathrm{L}$ ) and varying concentrations of whole venom and its fraction. Data are expressed as mean $\pm \operatorname{SEM}(n=4) .{ }^{*} p<0.05$ vs rabbit platelets.

marker of platelet activation - the LIBS1 epitope - on both human and rabbit platelets. Once platelets are activated, the GPIIb-IIIa complex suffers a conformational change and then anti-LIBS1 recognizes the epitope on the glycoprotein complex. ${ }^{23,33}$ In addition, L. gaucho venom-induced increased expression of P-selectin, a widely used marker of platelet activation, ${ }^{34}$ confirms the platelet activation state induced by the venom in both human and rabbit platelets. Thus, under in vivo conditions, P-selectin may play an important role in venominduced inflammation, especially in interactions between platelets and leukocytes/endothelial cells in the bite site. ${ }^{35}$

Loxosceles venoms have been investigated only for platelet aggregation activity; therefore, the present work is the first report about the platelet adhesion induced by a Loxosceles venom. L. gaucho venom induces a response that is independent of its concentration, whereas its sphingomyelinase fraction promotes a dose-dependent increase in platelet adhesion. A plausible explanation for this differential response is the existence of many components in Loxosceles venom - e.g., phosphatases, hyaluronidases, phosphohydrolases, metalloproteinases-, ${ }^{4,36}$ which may interfere in platelet adhesion to collagen, thus preventing the construction of a dose-response curve with the whole venom. On the other hand, the homogeneity of the adhesion results obtained with the sphingomyelinase fraction may encourage the use of this active fraction as a tool to future investigations about molecular mechanisms of platelet adhesion.

Studies about the biological actions of Loxosceles venoms have some limitations, and one of the most important is the spider's small size, which make possible to obtain only a tiny amount of venom for research purposes. Besides these difficulties, comparative studies about the biological effects of Loxosceles venoms and their toxins are important to understand and validate the pathophysiological phenomena occurring in human beings, since certain kind of cells from different species are affected by Loxosceles venoms in different ways. For instance, Loxosceles venoms promote hemolysis in humans ${ }^{9}$ but not in rabbits, neither in vitro ${ }^{37}$ nor in vivo. ${ }^{6}$ Thus, the rabbit is not a suitable animal model to study hemolytic disturbances, even though Barreto et al. ${ }^{38}$ reported that $L$. gaucho venom affects the resistance to both osmotic and shear stress of rabbit red cells in vivo. Regarding platelets, although our results evidence some differences between human and rabbit platelet sensitivity, platelets in both species presented a similar general pattern of response when they were exposed to the loxoscelic venom and its sphingomyelinase fraction.

The current results are in line with recent insights about the participation of platelets in inflammation. Platelet activation, adhesion and aggregation play a prominent role in homeostasis as well as in several pathological phenomena. Thus, platelets can link hemostasis and inflammation through the release of vasoactive monoamines (e.g., serotonin and histamine), chemokines (e.g., PF4/CXCL4, RANTES/ CCL5 and CXCL7) and cytokines (e.g., interleukin$1 \beta)$, and also through cell-to-cell interactions elicited by expression of adhesion and immunologically related molecules (e.g., P-selectin and 
CD40L). ${ }^{39-41}$ Taking into account this evidence and that Loxosceles venom-induced dermal necrosis involves hemostatic and inflammatory disturbances in its pathogenesis, platelets may play a pivotal role in the dermal necrosis, not only for their participation in local thrombotic disorders, ${ }^{6}$ but also for exacerbating the local inflammatory response induced by the Loxosceles venom.

In conclusion, our data demonstrate for the first time that $L$. gaucho venom and its sphingomyelinase fraction trigger the main platelet functions in both human and rabbit platelets, thus justifying the use of the rabbit as an experimental animal model to investigate the platelet disturbances induced by Loxosceles venoms. The role of platelets in the pathogenesis of loxoscelism should be addressed in further investigations, which may help to develop more efficacious therapeutic interventions following the envenomation.

\section{Acknowledgment}

We thank Marcela S Lira for her assistance with L. gaucho venom extraction.

\section{Funding}

This work was supported by FAPESP (process 03/00841-0), and it was part of the PhD thesis of F.L.T, accomplished at the Department of Pathology, Faculty of Veterinary Medicine and Zootechny, University of São Paulo, Brazil.

\section{References}

1. Hogan CJ, Barbaro KC, and Winkel K. Loxoscelism: old obstacles, new directions. Ann Emer Med 2004; 44: 608-624.

2. Pauli I, Minozzo JC, da Silva PH, Chaim OM, Veiga SS. Analysis of therapeutic benefits of antivenin at different time intervals after experimental envenomation in rabbits by venom of the Brown spider (Loxosceles intermedia). Toxicon 2009; 53: 660-671.

3. Sunderkotter C, Seeliger S, Schonlau F, Roth J, Hallmann R, Luger TA, Sorg C, Kolde G. Different pathways leading to cutaneous leukocytoclastic vasculitis in mice. Exp Dermatol 2001; 10: 391-404.

4. da Silva PH, da Silveira RB, Appel MH, Mangili OC, Gremski W, Veiga SS. Brown spiders and loxoscelism. Toxicon 2004; 44: 693-709.

5. Futrell JM. Loxoscelism. Am J Med Sci 1992; 304: 261-267.

6. Tavares FL, Sousa-e-Silva MC, Santoro ML, Barbaro KC, Rebecchi IM, Sano-Martins IS. Changes in hematological, hemostatic and biochemical parameters induced experimentally in rabbits by Loxosceles gaucho spider venom. Hum Exp Toxicol 2004; 23: 477-486.
7. Barbaro KC, Knysak I, Martins R, Hogan C, Winkel K. Enzymatic characterization, antigenic cross-reactivity and neutralization of dermonecrotic activity of five Loxosceles spider venoms of medical importance in the Americas. Toxicon 2005; 45: 489-499.

8. Paludo KS, Gremski LH, Veiga SS, Chaim OM, Gremski W, de Freitas Buchi D, Nader HB, Dietrich $\mathrm{CP}$, Franco CR. The effect of brown spider venom on endothelial cell morphology and adhesive structures. Toxicon 2006; 47: 844-853.

9. Tambourgi DV, Pedrosa MF, de Andrade RM, Billington SJ, Griffiths M, van den Berg CW. Sphingomyelinases D induce direct association of $\mathrm{Clq}$ to the erythrocyte membrane causing complement mediated autologous haemolysis. Mol Immunol 2007; 44: 576-582.

10. Veiga SS, Zanetti VC, Braz A, Mangili OC, Gremski $\mathrm{W}$. Extracellular matrix molecules as targets for brown spider venom toxins. Braz J Med Biol Res 2001; 34: 843-850.

11. Appel MH, da Silveira RB, Chaim OM, Paludo KS, Silva DT, Chaves DM, da Silva PH, Mangili OC, Senff-Ribeiro A, Gremski W, Nader HB, Veiga SS. Identification, cloning and functional characterization of a novel dermonecrotic toxin (phospholipase D) from brown spider (Loxosceles intermedia) venom. Biochim Biophys Acta 2008; 1780: 167-178.

12. da Silveira RB, Pigozzo RB, Chaim OM, Appel MH, Silva DT, Dreyfuss JL, Toma L, Dietrich CP, Nader HB, Veiga SS, Gremski W. Two novel dermonecrotic toxins LiRecDT4 and LiRecDT5 from brown spider (Loxosceles intermedia) venom: from cloning to functional characterization. Biochimie 2007; 89: 289-300.

13. Kurpiewski G, Forrester LJ, Barrett JT, Campbell BJ. Platelet aggregation and sphingomyelinase D activity of a purified toxin from the venom of Loxosceles reclusa. Biochim Biophys Acta 1981; 678: 467-476.

14. Rees RS, Gates C, Timmons S, Des Prez RM, King LE Jr. Plasma components are required for platelet activation by the toxin of Loxosceles reclusa. Toxicon 1988; 26: 1035-1045.

15. Barbaro KC, Cardoso JL, Eickstedt VR, Mota I. Dermonecrotic and lethal components of Loxosceles gaucho spider venom. Toxicon 1992; 30: 331-338.

16. Smith PK, Krohn RI, Hermanson GT, Mallia AK, Gartner FH, Provenzano MD, Fujimoto EK, Goeke NM, Olson BJ, Klenk DC. Measurement of protein using bicinchoninic acid. Analytical Biochem 1985; 150: 76-85.

17. Cunha RB, Barbaro KC, Muramatsu D, Portaro FC, Fontes W, de Sousa MV. Purification and characterization of loxnecrogin, a dermonecrotic toxin from 
Loxosceles gaucho brown spider venom. J Prot Chem 2003; 22: 135-146.

18. Santoro ML, Sousa-e-Silva MC, Gonçalves LR, Almeida-Santos SM, Cardoso DF, Laporta-Ferreira IL, Saiki M, Peres CA, Sano-Martins IS. Comparison of the biological activities in venoms from three subspecies of the South American rattlesnake (Crotalus durissus terrificus, C. durissus cascavella and C. durissus collilineatus). Compar Biochem Physiol-Part C: ToxicolPharmacol 1999; 122: 61-73.

19. Born GV. Aggregation of blood platelets by adenosine diphosphate and its reversal. Nature 1962; 194: 927-929.

20. Rother E, Brandl R, Baker DL, Goyal P, Gebhard H, Tigyi G, Siess W. Subtype-selective antagonists of lysophosphatidic Acid receptors inhibit platelet activation triggered by the lipid core of atherosclerotic plaques. Circulation 2003; 108: 741-747.

21. Burtis CA and Ashwood ER. In: Burtis CA, Ashwood ER (eds). Tietz Textbook of Clinical Chemistry Philadelphia: Saunders Company, 1999: 668-672.

22. Santoro ML, Barbaro KC, Flores da Rocha TR, Soares Torquato RJ, Hirata IY, Sano-Martins IS. Simultaneous isolation of platelet factor 4 and glycoprotein IIb-IIIa complex from rabbit platelets, and characterization of specific chicken antibodies to assay them. $J$ Immunol Meth 2004; 284: 55-72.

23. Ginsberg MH, Frelinger AL, Lam SC, Forsyth J, McMillan R, Plow EF, Shattil SJ. Analysis of platelet aggregation disorders based on flow cytometric analysis of membrane glycoprotein IIb-IIIa with conformation-specific monoclonal antibodies. Blood 1990; 76: 2017-2023.

24. Reed GL, Houng AK, and Bianchi C. Comparative biochemical and ultrastructural studies of P-selectin in rabbit platelets. Compar Biochem Physiol B: Biochem Mol Biol 1998; 119: 729-738.

25. Eriksson AC and Whiss PA. Measurement of adhesion of human platelets in plasma to protein surfaces in microplates. J Pharmacol Toxicol Meth 2005; 52: 356-365.

26. Malaque CM, Ori M, Santos SA, Andrade DR. Production of TNF-alpha by primary cultures of human keratinocytes challenged with Loxosceles gaucho venom. Rev do Inst Med Trop São Paulo 1999; 41: 179-182.

27. Patel KD, Modur V, Zimmerman GA, Prescott SM, McIntyre TM. The necrotic venom of the brown recluse spider induces dysregulated endothelial cell-dependent neutrophil activation. Differential induction of GM-CSF, IL-8, and E-selectin expression. J Clin Investigat 1994; 94: 631-642.
28. Lee S and Lynch KR. Brown recluse spider (Loxosceles reclusa) venom phospholipase D (PLD) generates lysophosphatidic acid (LPA). Biochem J 2005; 391: 317-323.

29. van Meeteren LA, Frederiks F, Giepmans BN, Pedrosa MF, Billington SJ, Jost BH, Tambourgi DV, Moolenaar WH. Spider and bacterial sphingomyelinases D target cellular lysophosphatidic acid receptors by hydrolyzing lysophosphatidylcholine. J Biol Chem 2004; 279: 10833-10836.

30. Zhao $\mathrm{Y}$ and Natarajan V. Lysophosphatidic acid signaling in airway epithelium: role in airway inflammation and remodeling. Cell Signal 2009; 21: 367-377.

31. Pamuklar Z, Lee JS, Cheng HY, Panchatcharam M, Steinhubl S, Morris AJ, Charnigo R, Smyth SS. Individual heterogeneity in platelet response to lysophosphatidic acid: evidence for a novel inhibitory pathway. Arterioscler, Thromb Vasc Biol 2008; 28: 555-561.

32. Bennett JS. Platelet-fibrinogen interactions. Ann New York Acad Sci 2001; 936: 340-354.

33. Frelinger AL, Cohen I, Plow EF, Smith MA, Roberts J, Lam SC, Ginsberg MH. Selective inhibition of integrin function by antibodies specific for ligand-occupied receptor conformers. J Biol Chem 1990; 265: 6346-6352.

34. Kajimoto H, Nakazawa M, Murasaki K, Hagiwara N, Nakanishi T. Increased P-selectin expression on platelets and decreased plasma thrombomodulin in Fontan patients. Circ J 2009; 73: 1705-1710.

35. Semple JW and Freedman J. Platelets and innate immunity. Cell Mol Life Sci 2010; 67: 499-511.

36. Senff-Ribeiro A, Henrique da Silva P, Chaim OM, Gremski LH, Paludo KS, Bertoni da Silveira R, Gremski W, Mangili OC, Veiga SS. Biotechnological applications of brown spider (Loxosceles genus) venom toxins. Biotechnol Adv 2008; 26: 210-218.

37. Futrell JM, Morgan BB, and Morgan PN. An in vitro model for studying hemolysis associated with venom from the brown recluse spider (Loxosceles reclusa). Toxicon 1979; 17: 355-362.

38. Barretto OC, Soeiro Prestes K, Figueiredo Fonseca LK, Achucarro Silveira PA. Functional alterations of rabbit erythrocytes induced by Loxosceles gaucho venom. Hum Exp Toxicol 2007; 26: 817-821.

39. Katoh N. Platelets as versatile regulators of cutaneous inflammation. J Dermatol Sci 2009; 53: 89-95.

40. Nurden AT, Nurden P, Sanchez M, Andia I, Anitua E. Platelets and wound healing. Front Biosci 2008; 13: 3532-3548.

41. von Hundelshausen P, Petersen F, and Brandt E. Platelet-derived chemokines in vascular biology. Thromb Haemost 2007; 97: 704-713. 